\title{
ANJOS MARCADOS: UM ESTUDO DA MICROCEFALIA NO CAMPO DA MEDICINA E DAS CIÊNCIAS JURÍDICAS NO BRASIL.
}

\section{MARKED ANGELS: A STUDY OF MICROCEPHALY IN THE FIELD OF MEDICINE AND LEGAL SCIENCES IN BRAZIL.}

\author{
${ }^{1}$ Frank Aguiar Rodrigues
}

\begin{abstract}
${ }^{1}$ Mestrando em Teoria do Direito e do Estado pelo Centro Universitário Eurípedes de Marília (UNIVEM - Marília/SP); Especialista em Direito Processual do Trabalho pela UNIDERP; Bacharel em Direito e Docente na Faculdade Vale do Itapecuru (CAXIAS-MA); Advogado. Email: frankaguiarrodrigues@ hotmail.com.
\end{abstract}

Resumo: O presente artigo aborda o tema ANJOS MARCADOS: Um estudo da microcefalia no campo da medicina e das ciências jurídicas no Brasil. O objetivo desse trabalho foi analisar os avanços e entraves sobre questões envolvendo crianças diagnosticadas com microcefalia. Para compreender o surto epidemiológico de microcefalia no país foi relevante realizar uma contextualização histórica dos casos dessa doença antes e após 2015. No segundo momento apresentam-se os direitos fundamentais das pessoas com deficiência, em particular a crianças com microcefalia causada pelo Zika vírus. Outro ponto que expôs nesse trabalho foi o uso de derivados da maconha para tratamento de saúde, seja o tratamento realizado de forma clandestina ou aquele que foi autorizado pela justiça. A metodologia utilizada nessa pesquisa é baseada na revisão bibliográfica. Adentrando ao campo da medicina e ao campo jurídico.

Palavras-chaves: Microcefalia; Tratamento; Direito.

Abstract: This article addresses the theme MARKED ANGELS: A study of microcephaly in the field of medicine and legal sciences in Brazil. The objective of this study was to analyze the advances and obstacles on issues involving children diagnosed with microcephaly. In order to understand the epidemiological outbreak of microcephaly in the country, it was important to carry out a historical contextualization of the cases of this disease before and after 2015. The second stage presents the fundamental rights of people with disabilities, in particular children with microcephaly caused by the Zika virus. Another point that he exposed in this work was the use of marijuana derivatives for health treatment, either the treatment carried out clandestinely or the one that was authorized by the courts. The methodology used in this research is based on the bibliographic review. Entering the field of medicine and the legal field.

Key-words: Microcephaly; Treatment; Right.

\section{INTRODUÇÃO}

A temática “ANJOS MARCADOS:

Um estudo da microcefalia no campo da medicina

e das ciências jurídicas no Brasil" nasceu da necessidade de se discutir essa nova realidade nosso Brasil, ocasionado pelo surto no ano de 2015 de casos de microcefalia relacionados a febre do Zika vírus, a região nordeste, em especial o estado de Pernambuco, foi a região onde se identificou o maior número de casos, esse acontecimento levou o Ministério da Saúde a decretar emergência em saúde pública no País.

Por ser a primeira vez em que se relatou uma possível associação causal entre uma arbovirose e malformações congênitas, posteriormente confirmada, o Brasil classificou o evento como incomum/inesperado. Além do Ministério da Saúde, a Organização Mundial de Saúde também se posicionou mediante esse aumento significativo de casos de síndromes 
neurológicas e de casos de microcefalias potencialmente relacionados ao vírus da zika, declarando Estado de Emergência em Saúde Pública Internacional.

A literatura sobre essa temática ainda é principiante, porém a relevância desses casos contribuíram para a realização de estudos sobre a microcefalia, o próprio Ministério da Saúde viabilizou estudos sobre essa temática, como o artigo "Microcefalia no Brasil: prevalência e caracterização dos casos a partir do Sistema de Informações sobre Nascidos Vivos (Sinasc), 20002015, cujo objetivo é descrever os coeficientes de prevalência e caracterizar os casos de microcefalia ao nascer no Brasil no recorte temporal acima mencionado, é válido ressaltar que os casos de microcefalia não é um agravo novo, ou seja, já existiam casos no país com essa anomalia, mas relacionados a esse vírus é recente.

Outros trabalhos que nortearam nossos estudos foram: Características dos primeiros casos de microcefalia possivelmente relacionados ao vírus Zika notificados na Região Metropolitana de Recife, Pernambuco, Zika virus associado a microcefalia, dentre outros no viés da medicina, para o referencial jurídico será utilizada a Constituição Federal de 1988, além do trabalho de Ana Clara Gonçalves Discacciati: A possibilidade de concessão de benefício assistencial a famílias com crianças portadoras de necessidades especiais no qual a autora busca analisar juridicamente uma possível alternativa para a atual conjuntura de nascimento de crianças com microcefalia no Brasil.

O objetivo desse trabalho é analisar os avanços e limitações sobre questões de direito, em crianças diagnosticadas com microcefalia, para tanto o presente artigo foi dividido em três seções, que serão trabalhadas da seguinte forma: no $1^{\circ}$ capítulo: "A MICROCEFALIA NO BRASIL ANTES E DEPOIS DO SURTO DE 2015”, onde será abordado o contexto histórico sobre os casos de microcefalia no Brasil e no mundo, além de apresentar as ações tanto do Ministério da Saúde, quanto da Organização Mundial da Saúde para combater essa epidemia. Com a temática: "PELO CRIVO DA LEI: DIREITOS FUNDAMENTAIS ÀS CRIANÇAS COM DEFICIÊNCIA", o $2^{\circ}$ capítulo apresentará a luta pelos direitos das pessoas com deficiência, enfatizando os direitos das pessoas com microcefalia e no último capítulo "FOLHAS QUE SE TRANSFORMAM EM PÓ: O USO DA MACONHA PARA TRATAMENTO DE SAÚDE" analisará os benefícios do uso dessa planta e seus derivados.

Este artigo conta com autores como Marinho (2016), Vargas (2016) como referenciais teóricos. No campo jurídico tem-se como suporte a Constituição Federal de 1988, Discacciati (2016); no campo da medicina será utilizado Bueno (2016), Menezes (2016), dentre outros.

\section{A MICROCEFALIA NO BRASIL ANTES E DEPOIS DO SURTO DE 2015}

A microcefalia é avaliada como uma doença grave, mas não é um agravo novo, porém a sua associação ao zika vírus é recente e em decorrência do aumento de casos no Brasil no ano de 2015 o Ministério da Saúde apresentou um estudo sobre os coeficientes de prevalência 
caracterizando os casos de microcefalia no nascimento no período de 2000 a 2015. É importante primeiramente entender o que é essa patologia.

A microcefalia é uma malformação congênita em que o cérebro não se desenvolve de maneira adequada: o perímetro cefálico dos recém-nascidos é menor que dois desvios-padrão da média para idade e sexo, podendo levar a alterações cerebrais e problemas no desenvolvimento neurológico. (VARGAS et. al. 2016: 692)

O agente causador do vírus zika é o Aedes aegypti um vírus bastante conhecido no país por causar doenças como a dengue e a chikungunya. A manifestação do vírus Zika sucede uma febre no qual apresenta um quadro de exantema pruriginoso, acompanhado ou não de febre baixa e outros sinais inespecíficos, como mialgia, cefaleia, artralgia e hiperemia conjuntival. Devido os sintomas serem parecidos com o da dengue, embora mais brandos, é provável que os dados de contágios tenham sido subestimados e por esse motivo não terem sido agrupado nas doenças de notificação compulsória pelo Ministério da Saúde.

Anterior a epidemia do zika vírus ocorrido no Brasil o conhecimento sobre essa doença era limitado, esporadicamente houveram surtos do vírus em duas regiões da Oceania, na Micronésia e na Polinésia Francesa, está última onde teria ocorrido o maior número de casos até então, 17 (dezessete) episódios entre março de 2014 e maio de 2015 diagnosticado a malformações do sistema nervoso central, incluindo microcefalia, em fetos e recém-nascidos.
Os dados sobre os casos na Oceania constataram que:

$[\ldots]$ a ocorrência de
aproximadamente 30.000
infecções e observaram-se pela
primeira vez os casos de
síndrome de Guillain-Barré
(SGB) associada às infecções
pelo ZIKV e a notificação dos
primeiros casos de transmissão
perinatal, que alertou para o
potencial das complicações das
infecções congênitas por
arbovírus, com base em relatos
anteriores de encefalopatia,
febre hemorrágica, óbito fetal,
dentre outros, associados aos
vírus chikungunya e dengue.
(OLIVEIRA et al, 2016: 103)

Segundo as autoridades da Polinésia Francesa o fato das gestantes terem sido infectadas no primeiro e/ou segundo trimestre de gestação possibilita relacionar essas anomalias congênitas ao vírus zika.

No Brasil, o Nordeste foi a região mais afetada com a epidemia, em especial, o Estado do Pernambuco que identificou através da Secretaria Estadual de Saúde (SES/PE) 54 (cinquenta e quatro) ocorrências na região de recém-nascidos com microcefalia, notificados em 22 de outubro de 2015 o Ministério da Saúde rapidamente enviou técnicos da Secretaria de Vigilância em Saúde para compor a equipe local e cooperar com a investigação epidemiológica. Outros estados do Nordeste com casos de microcefalia foram Paraíba, Bahia, Ceará, Rio Grande do Norte, Sergipe, Alagoas, Maranhão, Piauí; no sudeste existe o Rio de Janeiro; no Centro-oeste: Goiás, Distrito Federal e Mato Grosso do Sul e no norte: Tocantins.

O alto índice de ocorrências de casos de microcefalia contribuiu para que o Ministério da 
Saúde decretasse o episódio como emergência em Saúde Pública de importância nacional. Um dos fatores que colaborou para essa classificação foi por ser um evento incomum/inesperado.

\begin{abstract}
No Brasil, o evento da epidemia de microcefalia concomitante com a circulação do vírus Zika significou a primeira vez em que se relatou uma possível associação causal entre uma arbovirose e malformações congênitas, posteriormente confirmada. (VARGAS et al, 2016: 697)
\end{abstract}

O alerta não se restringiu apenas aos órgãos do país, em fevereiro de 2016 a Organização Mundial de Saúde (OMS) também se posicionou mediante esse aumento significativo de casos de síndromes neurológicas e de casos de microcefalias potencialmente relacionados ao vírus da zika, declarando Estado de Emergência em Saúde Pública Internacional. Anterior a esse episódio a OMS havia declarado estado de emergência global para uma epidemia viral nos casos de H1N1 (2009), poliomielite (2014) e ebola (2014) (FALCÃO, 2016).

Uma das políticas adotadas pelo Ministério da Saúde para combater à epidemia do zika vírus foi a união com as pastas da Educação, Desenvolvimento Social e Defesa baseando-se em três pilares principais com uma atuação intersetorial.

O primeiro é a Mobilização e combate ao vetor, centrado em vigilância epidemiológica articulada nos três níveis de governo, controle do mosquito e seus focos, ações relativas ao saneamento básico (água e eliminação de resíduos sólidos), estratégias comunicacionais com a criação de campanhas de conscientização e disseminação
DOI: $10.29247 / 2358-260 X .2018 v 5 i 2 . p 14-28$

de informações. O segundo, é o Cuidado, que abarca ações relativas ao desenvolvimento de protocolos e diretrizes de diagnóstico e tratamento, organização da rede de atendimento e capacitação de recursos humanos. E o terceiro, é o desenvolvimento tecnológico, educação e pesquisa, com o lançamento de editais de fomento à investigação de diagnóstico, controle vetorial, protocolos e diretrizes de manejo clínico, vacinas e tratamentos, educação. (BUENO 2016: 11).

A parceria entre essas Pastas com o objetivo de controlar esse surto e as medidas adotadas baseadas nesses três pilares foram fundamentais enquanto políticas de controle, além disso pode-se apontar a cooperação internacional como um quarto pilar, visto que a gravidade dessa epidemia fez com que a OMS convocasse um Comitê de Emergência, essa comissão enunciou duas recomendações, a primeira consistia em padronizar e incrementar a vigilância nas áreas afetadas pelo zika, já a segunda foi o aumento de pesquisas sobre a etiologia desse surto e verificar a relação causal com o vírus.

Conforme os estudos realizados aqui no Brasil o Zika vírus pode ser identificado através de exame laboratorial com a detecção de RNA viral a partir de espécimes clínicos. O Instituto Evandro Chagas (IEC) foi o responsável pelo teste sorológico e a relação da sequência genética completa do Zika vírus. Por ser um vírus de curta duração orienta-se que o exame seja feito até o $5^{\circ}$ dia da manifestação dos sintomas. É importante ressaltar que há por parte dos laboratórios de referência um esforço coletivo para o 
desenvolvimento de plataformas para a realização de provas sorológicas específicas ${ }^{1}$.

O Ministério da Saúde tem reforçado algumas recomendações às gestantes, dentre elas o não uso medicamentos não prescritos pelos profissionais de saúde; a importância do pré-natal e todos os exames previstos nesta fase; relatar aos profissionais de saúde qualquer alteração que perceberem durante a gestação. Além do uso de repelentes, uso de roupas de manga comprida e todas as outras medidas para evitar o contato com mosquitos, além de evitar o acúmulo de água parada em casa ou no trabalho. Independente do destino ou motivo, toda grávida deve consultar o seu médico antes de viajar.

Embora ainda não haja um tratamento específico para a microcefalia, mas existe uma classificação para ela em primária e secundária. No primeiro caso a categorização decorre quando os ossos do crânio se fecham durante a gestação, ainda aos 7 (sete) meses de gestação, o que origina maiores complicações durante a vida, na secundária os ossos se fecham no fim da gravidez ou após o bebê nascer.

Dentre as medidas que podem ser tomadas para amenizar os problemas destas crianças, estão a intervenção cirúrgica a fim de afastar ligeiramente os ossos cranianos, no período dos dois primeiros meses de vida, com o objetivo de impedir seu crescimento evitando assim a compressão do cérebro. Até o primeiro ano de vida da criança com microcefalia identificasse os cuidados que elas precisarão ter por toda a vida, dentre as consequências mais graves que acomete as pessoas com microcefalia destaca-se: o atraso mental, déficit intelectual, paralisia, convulsões, epilepsia, autismo, espasticidade. O portador de microcefalia precisará de um acompanhamento de uma equipe multiprofissional durante toda sua vida.

\section{PELO CRIVO DA LEI: DIREITOS FUNDAMENTAIS AS PESSOAS COM DEFICIÊNCIA}

É relevante contextualizar como as pessoas com deficiência foram conquistando seus direitos, visto que foi um processo lento e gradativo marcado por uma luta árdua, mas que através destes permitiu-lhes adentrar espaços outrora limitados, dentre eles: a escola, o mercado de trabalho, lazer e outros.

A pessoa com deficiência durante muito tempo esteve a margem da sociedade, uma das primeiras políticas voltadas a esses sujeitos foram o assistencialismo.

O assistencialismo foi, por
muitas gerações, a resposta
encontrada.
governamentais baseavam-se
numa visão paternalista,
desconsiderando os potenciais
das PPDs. Esta visão tinha
como grande problema o
afastamento destas pessoas da
vida e sociedade, o total
alijamento da PPD da
comunidade e da possibilidade
de influenciar nos destinos da
comuna. (DIAS, S/D, p. 2)

Essa visão paternalista que nos apresenta Dias não visava a integração da pessoa com deficiência ao meio social permitindo socializar-se igualitariamente, mas limitava-o, pois 
não havia o objetivo de valorizar a autonomia destes sujeitos, tão pouco o direito a dignidade destes indivíduos.

A pessoa com deficiência passa a ser percebido enquanto sujeito a partir da política de reintegração que surge com organizações e entidades na Europa e Estados Unidos logo após alguns episódios históricos, dentre os quais: a Revolução Industrial e a $1^{\mathrm{a}}$ e $2^{\mathrm{a}}$ guerras mundiais.

A Declaração dos Direitos das Pessoas Deficientes sem dúvidas é considerado um divisor de águas para as pessoas com deficiência ao garantir e promover o direito de todos os cidadãos em 1975.

Para garantir as pessoas com deficiência tanto apoio, quanto sua integração social foi criada no Brasil a Lei $\mathrm{n}^{\circ} 7.853$, de 24 de outubro de 1989, a através da Coordenadoria Nacional para Integração da Pessoa com Deficiência (Corde).

\section{Corpos marcados: a microcefalia causada pelo Zika Vírus}

A microcefalia é uma doença que pode ser diagnosticada ainda na gestação através de exames do pré-natal, dentre eles a ultrassonografia e a confirmação com a mensuração do tamanho da cabeça do bebê logo após o parto. É relevante mencionar que o surto de casos de microcefalia que atingiu o Brasil trouxe um impacto emocional a essas famílias.

A gravidez em si já é um momento de incertezas para algumas mulheres, em especial as primíparas, pois os pais esperam com muita ansiedade a criança, e ao saber que elas possuem alguma deficiência, eles enfrentam duas crises principais, segundo Faber:

A primeira é um tipo de morte
simbólica, ou seja, a decepção
dos sonhos, dos objetivos,
desejos, etc. Acabam gerando
nos pais reações diversas, uma
dolorosa ferida, cuja
cicatrização passa por algumas
etapas, por exemplo: choro,
desespero, frustração, raiva,
rejeição, sentimento de culpa,
até chegar à aceitação. A
segunda se relaciona aos
cuidados coma criança, ou seja,
uma alimentação saudável,
equipamentos caros,
tratamento multidisciplinar, e
isso acarretam gastos
financeiros muito elevados.
(FABER 1976)

Independentemente das condições físicas que envolve um recém-nascido a família enquanto instituição tem a obrigação de proteger, amar, educar, mas muitas famílias não têm estrutura financeira para cuidar de uma criança com uma anomalia tão grave. Alguns pais e mães após o fim da licença-maternidade terão dificuldades de gerir os dispêndios da criança, além de existir a possibilidade de não retornar ao mercado de trabalho devido a necessidade de uma assistência ininterrupta ao filho deficiente.

A deficiência é um fenômeno global, frequentemente associado à pobreza, com impactos políticos, econômicos, culturais e sociais, e implicações para a sociedade como um todo ${ }^{2}$. A Organização das Nações Unidas, classifica a deficiência em duas categorias: "deficiências graves ou moderadas", nos dados fornecidos por essa instituição no ano de 2004 estima-se que 15,3\% da 
população mundial (cerca de 978 milhões de pessoas dos estimados 6,4 bilhões de habitantes) enquanto 2,9\% ou cerca de 185 milhões enfrentavam "deficiências graves". Já no Brasil a população com alguma deficiência corresponde a cerca de 45,6 milhões, o que corresponde a 23,92\% da população brasileira. (OUTTES, 2016)

Como a abordagem da deficiência é especificamente a microcefalia, é extremamente importante analisar os dados coletados pelo Ministério da Saúde entre os anos de 2000-2015 sobre os casos de microcefalia no país. Identificouse que:

Os coeficientes de prevalência de microcefalia foram maiores entre nascidos vivos de mães com as seguintes características: idade até 24 ou 40 anos e mais, pretas ou pardas, sem curso superior, residentes na região Nordeste do país, e que se declararam solteiras ou em união estável. Apesar de o presente estudo não incluir a variável "renda", por esta não estar contemplada no Sinasc, esses resultados reúnem variáveis proxy que possibilitam considerar que a maioria das mães de nascidos vivos com microcefalia estão inseridas em um contexto socioeconômico desfavorável. (MARINHO et. al. 2016: 707)

Conforme alerta Marinho um dos fatores preponderante para infecção do vírus da Zika é o contexto socioeconômico, assim outros elementos devem ser salientados dentre eles a moradia, urbanização, saneamento básico, dentre outros.

Para a Associação Brasileira de Saúde Coletiva (Abrasco) em meio aos fatores oriundos do surto de casos de microcefalia estão:
DOI: 10.29247/2358-260X.2018v5i2.p14-28

“[...] as precárias condições de moradia, de urbanização e de saneamento ambiental, contexto característico da grande maioria dos casos de microcefalia, refletem um modelo de desenvolvimento e de políticas urbanas que atinge aos pobres, já vulnerabilizados historicamente pela abissal desigualdade social brasileira. Habitações sem condições para adequado armazenamento de água domiciliar, localizadas em áreas íngremes ou alagadas, com precária infraestrutura $\mathrm{e}$ urbanização e com serviços de saneamento precários. Um contexto que reflete a mazela social que destina melhor infraestrutura e melhores serviços para as classes média e alta".

(http://averdade.org.br/2016/ $\underline{03 / 16188 /)}$

É importante observar que no Brasil existem políticas públicas voltadas as pessoas com deficiências e que nos últimos anos se tem "avançado na promoção dos direitos das pessoas com deficiência por meio de políticas públicas que buscam valorizar a pessoa como cidadã, respeitando suas características e especificidades". (OUTTES, 2016)

Mas também é oportuno ressaltar que esses direitos foram sendo conquistados a partir do avanço no processo de politização dos sujeitos sociais comprometendo o Estado a responsabilizar-se cívica e eticamente no desenvolvimento de políticas públicas de proteção social destinadas a atender as demandas desse segmento social.

A Política Nacional para a Integração da Pessoa com Deficiências (PNIPcD) inserida no Decreto $n^{\circ} 3.298 / 99$, sancionado em dezembro de 1999 é uma conquista que resulta dos esforços dos movimentos sociais e da proteção legal da 
Coordenação Nacional para Integração da Pessoa

Portadora de Deficiência.

\begin{abstract}
Esse postulado legal contém um conjunto de orientações normativas que objetivam assegurar a esses sujeitos o pleno exercício dos direitos no campo da saúde, educação, habilitação e reabilitação, trabalho, cultura, turismo e lazer. (FRANÇA 2007:113)
\end{abstract}

Compete analisar a PNIPcD pelo fato de que apesar do respaldo jurídico que a Constituição Federal apresenta ao cidadão "Dos Direitos e Deveres Individuais e Coletivos" no Art. $5^{\circ}$, o mesmo não atende à demanda, excluindo alguns sujeitos e sendo necessário outras prerrogativas para atendê-los e assim usufruir do pleno exercício dos direitos.

No tocante a assistência da criança com microcefalia no campo da saúde é importante advertir a falta de tratamento específico e em decorrência de diversas complicações desenvolvidas por essa doença a necessidade de um acompanhamento por multiprofissionais, as principais dificuldades enfrentadas por essas crianças serão "dentre elas respiratórias, neurológicas e motoras e o acompanhamento por diferentes especialistas vai depender de quais funções ficaram comprometidas. (FALCÃO 2016, p. 19). Os principais profissionais no acompanhamento das crianças microcefalia são: pediatra, neurologista, psicólogos, dentista, terapeuta ocupacional, fonoaudiólogo e em especial o fisioterapeuta, por ser esse especialista responsável em ajudar o paciente no desenvolvimento físico e mental.
DOI: $10.29247 / 2358-260 X .2018 v 5 i 2 . p 14-28$

A necessidade de constante acompanhamento da criança por profissionais de saúde e de assistência social, no intuito de proporcionar-lhe o melhor desenvolvimento psíquicomotor possível, implica no dispêndio de recursos materiais, a ser arcado pelo Estado, bem como de tempo, que, por muitas vezes, afasta um dos pais do mercado de trabalho.

(DISCACCIATI 2016: 240)

Conforme mencionado outrora, a maioria dos casos de microcefalia são oriundas de famílias de baixa renda, portanto incapazes de custear o tratamento dessas crianças. Partindo desse pressuposto o governo Federal sancionou a Lei 13.301/2016, que dá o direito as crianças com microcefalia ao Benefício da Prestação Continuada Temporário (BPC). Dentre os critérios exigidos para receber o BPC, no valor de um salário mínimo, enfatiza-se a renda familiar que não poderá ultrapassar $1 / 4$ do salário mínimo por pessoa e o prazo de até três anos desse auxílio.

\section{FOLHAS QUE SE TRANSFORMAM EM PÓ: O USO DA MACONHA PARA TRATAMENTO DE SAÚDE}

O tratamento à base da maconha é uma prática bastante antiga, um dos primeiros relatos do uso dessa substância para fins terapêuticos data de 2.300 a.C., pelo imperador chinês Shen Nung para tratamento de dores, malária e constipação. Quanto a nomenclatura e origem da maconha ressalta-se:

O nome científico da maconha é Cannabis sativa. Em latim, Cannabis significa cânhamo, que denomina o gênero da família da planta, e sativa que diz respeito plantada ou 
semeada, e indica a espécie e a natureza do desenvolvimento da planta. É uma planta originária da Ásia Central, com extrema adaptação no que se refere ao clima, altitude, solo, apesar de haver uma variação quanto à conservação das suas propriedades psicoativos, podendo variar de 1 a $15 \%$ dependendo da região à qual foi produzida a erva e a forma como foi ingerida, pois esta requer clima quente e seco, e umidade adequada do solo (GONTIÈS apud Bergeret \& Leblanc, 1991; Costa \& Gontiès,1997; Nahas, 1986).

No Brasil a introdução desta planta é atribuída aos escravos africanos. Porém por ordem da Coroa portuguesa no século XVIII foi incentivado o plantio da Cannabis, contudo o consumo difundiu-se entre os negros escravos e índios, ou seja, o consumo prevaleceu nas camadas sociais menos favorecidos. Esse quadro foi modificado, a partir da segunda metade do século XIX, decorrente da divulgação dos estudos do francês Jean Jacques Moreau sobre os efeitos hedonísticos dessa planta sendo aceito pela classe médica para uso medicinal, dentre os tratamentos de doenças como: "bronchite crônica das crianças (...) na asthma, na tísica laryngea, (...)”’3.

Nos compêndios médicos e catálogos de produtos farmacêuticos na década de 1930 ainda é citada o uso da maconha dentre as funções terapêuticas destaca-se: calmante e antiespasmódico, e no tratamento de doenças “dyspepsias (...) no cancro e úlcera gástrica (...) na insomnia, nevralgias, nas perturbações mentais ... dysenteria chronica, asthma, etc." ${ }^{4}$, pode-se

${ }^{3}$ CARLINI, EA, RODRIGUES E, GALDURÓZ JCF. Cannabis sativa $L$. e substâncias canabinóides em medicina. São Paulo: CEBRID, 2005. p. 315 observar que a maconha no decorrer do tempo foi sendo cada vez mais utilizada para tratamento de algumas enfermidades. Contudo, nesse mesmo período iniciou-se a repressão do seu uso por iniciativa do delegado Pernambuco ao propor juntamente com o delegado egípcio o combate ao seu uso na II Conferência Internacional do Ópio, em 1924, na Genebra. Os estados brasileiros duramente reprimidos foram Rio de Janeiro, Pernambuco, Maranhão, Piauí, Alagoas e Bahia. O Rio de Janeiro registrou as primeiras prisões pela comercialização da maconha.

A partir de 1938 o Brasil passou a proibir em todo território nacional o plantio, cultura e colheita e exploração por particulares da maconha através do Decreto-Lei no ${ }^{\circ}$ 991. Embora a maconha não seja uma substância narcótica, ela foi posta nessa convenção de entorpecentes e a Lei ${ }^{\circ}$ 6.368, no ano de 1976, predizendo como pena por porte a prisão, seja qualquer quantia, mesmo que para uso pessoal. Existe atualmente um projeto no Congresso Nacional que se encontra em fase final para alterar a penalidade da lei de prisão a sanções administrativas, no caso específico do porte de maconha em pequena quantidade e para uso particular.

No artigo "Maconha medicinal: o direito à saúde versus o uso de substâncias entorpecentes" de autoria de Moura aponta como um dos fatores inviáveis ao uso da maconha medicinal a escassez de pesquisas.

A proibição da maconha no país também faz com que não 
DOI: 10.29247/2358-260X.2018v5i2.p14-28

seja fácil ter acesso à planta para o desenvolvimento de pesquisas. E é justamente pela escassez de estudos que a Anvisa alegava que seria inviável a liberação do uso medicinal da cannabis, isto é, não havia pesquisas porque era proibido, e era proibido porque não havia pesquisa. (MOURA, 2016, et al, P.9)

Enquanto no Brasil a erva continua sendo proibida, em diversos outros países as pesquisas são incentivadas para que a mesma possa ser usada em diversas enfermidades, esses estudos que vem sendo realizado a algum tempo ressalta o alto poder terapêutico da maconha. Cientificamente a maconha já foi testada e comprovado que em tratamentos de diversas doenças o seu uso é eficaz, em especial na terapia de raras doenças e ou como um tratamento alternativo.

No ano de 1965 o cientista Rafael Mechoulam da Universidade Hebraica de Jerusalém descobriu a molécula mais psicoativa da planta ao isolar o componente da Cannabis - o Delta 9 Tetrahidrocanabinol, ou THC, contribuindo para a ciência moderna o estudo sobre essa planta. O THC tem atuação como relaxante muscular e anti-inflamatório na sua composição física; já na função psicológica age como estimulante. O THC causa efeito analgésico e seu uso trata dores, para aumentar o apetite. Dentre os efeitos ressalta-se: Anticonvulsivo, Antiinflamatório, Antidepressivo, Estimulante do apetite e Diminuição da pressão arterial.

$$
\text { Outro componente relevante nos }
$$
estudos sobre essa erva é o Canabidiol (CBD). Segundo Moura et al o CBD "ao entrar na corrente sanguínea e chegar ao cérebro, ela 'acalma' a atividade química e eletric excessiva do órgão", as pesquisas do psiquiatra e neurocientista José Alexandre Crippa sobre o CBD corrobora que o mesmo possui diversas características benéficas no tratamento de "esquizofrenia, Parkinson, fobia social, transtorno do sono, diabetes tipo 2 e mesmo na cura da dependência de drogas, tendo propriedades medicinais como anticonvulsivante, anti-inflamatório, antipsicótico, antioxidante, neuroprotetor e imuno-modulador" (MOURA, 2016).

\section{Entre as tramas da lei: ações judiciais para} tratamento à base da maconha.

O Brasil ainda é um dos Estados que não reconhece os poderes terapêuticos da maconha, essa proibição acaba restringindo o direito de inúmeras pessoas que padecem de doenças raras impedindo-as de tratarem-se ou amenizarem os sintomas oriundos desses males com substâncias derivadas e ou até mesmo da própria maconha.

Embora seja proibido produtos medicamentos à base da maconha seu uso cresce a cada dia por um grande número de pessoas, visto que os resultados são perceptíveis em pouco tempo em decorrência do seu alto poder terapêutico.

A proibição do uso da maconha para fins terapêuticos feri a Constituição Federal de 1988 em seus artigos 6, 196 e 197 quando a mesma nos garante a preservação da saúde como um direito social. Deve-se Analisar o art. 196 quanto a obrigação do Estado sobre as suas ações para promoção da saúde. 
Art.196 "A saúde é direito de todos e dever do Estado, garantido mediante políticas sociais e econômicas que visem à redução do risco de doença $\mathrm{e}$ de outros agravos e ao acesso universal e igualitário às ações e serviços para sua promoção, proteção e recuperação". (BRASIL 2012, p. 54).

O não cumprimento do Estado ao direito social a saúde não segurado na Constituição Federal contribui para que a população busque outros mecanismos para adquirir os produtos medicamentos à base da maconha, são eles: o tráfico da droga e através de ações judiciais.

Moura et al (S/A) descrevem a forma de aquisição da maconha por algumas famílias.

Muitas famílias traficam tais produtos ou adquirem as substâncias vindas de laboratórios caseiros e clandestinos. Como as substâncias são ilícitas, assim como a planta ou a produção dela, geralmente não há acompanhamento médico nestes tratamentos. Desta maneira, o Estado não só restringe o direito à saúde destes, como também prejudica os eventuais tratamentos que poderiam ser mais eficazes. (MOURA, 2016, et al, S/A, p.1)

A violação da lei é um problema gravíssimo, porém recorrer a essa prática do tráfico é uma das possibilidades aos resultados positivos dos pacientes mediante o uso desses produtos.

Quanto as ações judiciais para autorizar o uso de medicamentos a base da maconha, podem se fundamentar na própria Carta Magna para garantir o direito à saúde.

São amplas as possibilidades de concretização judicial deste direito, sobretudo se houver sempre em mente o princípio da máxima efetividade das normas constitucionais. Tais dispositivos não hão de ser vislumbrados como apenas mais uma regra jurídica inócua e sem efetividade, ou seja, é preciso evitar que os princípios e fundamentos da República virem letra morta. (MOURA, 2016, et al, S/A, p.2)

Atualmente a menina Anny Fischer representa simbolicamente a luta pela importação do CBD para fins terapêuticos, Anny possui uma forma rara e grave de epilepsia.

Anny é portadora de uma epilepsia refratária, a síndrome CDKL5, uma doença genética rara, que causa epilepsia grave, que levava a ter 80 convulsões por semana, isto é, convulsões de 2 em 2 horas. A menina tomava altas doses de variados remédios que, além de trazerem efeitos colaterais indesejáveis, não surtiam efeitos positivos. Foi quando a família da garota descobriu que outra criança americana, que tinha a mesma doença de Anny, estava tendo resultados ótimos usando o Canabidiol (CBD), uma das 400 substâncias derivadas da maconha. Os pais da garota não pensaram duas vezes $\mathrm{e}$ importaram o produto, que é considerado nos Estados Unidos como suplemento, diferentemente do Brasil, que tem a substância como proibida por se derivar da maconha. A família conseguiu um contato nos Estados Unidos, que fazia a compra da substância e logo depois de camuflar a enviava ao Brasil, ou seja, o suplemento era traficado. (MOURA, 2016, et al, S/A, p.6)

O caso de Anny Fischer trouxe à tona a discussão de um assunto outrora evitado, tanto pela sociedade quanto pelas instituições como o poder Judiciário e Legislativo que é o uso da 
maconha medicinal. Anny Fischer conseguiu através de uma liminar a autorização para uso e importação de medicamento derivado da Cannabis sativa (maconha) sendo a primeira vez na história do Brasil que a justiça autoriza essa concessão. No entanto, o juiz da $3^{\text {a }}$ Vara Federal de Brasília, Bruno Apolinário ressalta os pressupostos para autorização ao caso de Anny Fischer.

Apolinário, porém, diz que a decisão é exclusiva para esse caso. "Não se pretende com a presente demanda fazer apologia do uso terapêutico da Cannabis sativa (...) menos ainda da liberação de seu uso para qualquer fim em nosso país (...) A substância revelouse eficaz na atenuação ou bloqueio das convulsões, (...) dando-lhe uma qualidade de vida jamais experimentada". (OLIVEIRA 2014, p. 1)

Notando os benefícios do uso medicinal da maconha para tratamentos de diversas doenças, é importância trazê-la para pauta a discussão sobre sua legalização. É relevante frisar que distintos casos já analisam seu uso para tratamento, o Centro Integrado de Reabilitação (Ceir) do Piauí iniciará uma pesquisa sobre o uso do Canabidiol para tratar as crises convulsivas das crianças com microcefalia.

A pesquisa contará com diversas instituições como a Universidade Federal do Piauí (UFPI), a Universidade Estadual do Piauí (UESPI) e a Fundação de Amparo à Pesquisa do Estado do Piauí (Fapepi). O grupo de estudos dessa pesquisa serão as crianças com microcefalia. Esse projeto ainda está em fase de elaboração e discussão junto a comissão ética para avaliar cientificamente o uso do canabinóide nas crises convulsivas refratárias.

DOI: 10.29247/2358-260X.2018v5i2.p14-28

É relevante ressaltar a importância do

Centro Integrado de Reabilitação no desenvolvimento dessa pesquisa. Apesar de ser uma instituição nova, com apenas 9 anos de criação, o Ceir atende uma clientela de 1.400 pessoas mensalmente. E dentre as políticas desse Centro está o fortalecimento das pesquisas cientificas. Segundo (MORAES 2017, P.1):

\begin{abstract}
A nossa missão no Ceir é o cuidado com as pessoas. Dedicar às pessoas com necessidades especiais o nosso talento, que é o que nós fazemos. Sempre digo que não cuidamos de doenças e nem de doente, nós cuidamos das pessoas para que elas consigam conviver com sua deficiência normalmente. Fazemos a inclusão social.
\end{abstract}

Diante da peculiaridade advinda com o surto de casos de microcefalia em 2015 é relevante que os Centros Integrado de Reabilitação enquanto espaço de acolhimento estejam preparados para receber essas crianças, respeitando acima de tudo o direito enquanto sujeito social.

\section{CONSIDERAÇÕES FINAIS}

Diante do que foi discutido no decorrer desse artigo e preciso fazer algumas considerações. No primeiro momento explanar a dificuldade de abordar essa temática, embora a microcefalia seja uma patologia já conhecida, a repercussão nos casos dela associada ao zika vírus agente causador do Aedes aegypti alarmou o Brasil a partir de 2015. Para diagnosticar os fatores que determinaram essa epidemia o Ministério da Saúde em parceria com a Secretaria Estadual de Saúde (SES/PE), primeira região a identificar casos de 
microcefalia, produziram trabalhos com a finalidade de caracterizar os primeiros casos dessa doença e realizar um levantamento de dados de 2000 a 2015.

Por se tratar de um evento incomum/inesperado e devido ao alto índice de ocorrências de casos de microcefalia o Ministério da Saúde decretou esse episódio como emergência em Saúde Pública de importância nacional. A Organização Mundial de Saúde declarou no ano de 2016 Estado de Emergência em Saúde Pública Internacional mediante esse aumento significativo de casos de síndromes neurológicas e de casos de microcefalias potencialmente relacionados ao vírus da zika. Após a convocação pela Diretora Geral da OMS, Margaret Chan, aprovou-se o Comitê de Emergência e dentre as duas principais recomendações emitidas pelo comitê estão: padronizar e incrementar a vigilância de microcefalia nas áreas afetadas pelo Zika e a segunda foi aumentar a pesquisa sobre a etiologia desses surtos para determinar se há relação causal com o vírus.

Diante das leituras pode-se identificar que os fatores principais para infecção do vírus da Zika estão associados ao contexto socioeconômico, assim outros elementos devem ser salientados dentre eles a moradia, urbanização, saneamento básico, dentre outros.

Ressaltar que a assistência da criança com microcefalia no campo da saúde necessitará de um acompanhamento por multiprofissionais. Porém a maioria das famílias não terão condições de custear um tratamento e que caberá ao Estado custeá-lo. Divulgar as famílias a importância do
Benefício da Prestação Continuada Temporário (BPC) para auxiliar na assistência da criança com microcefalia. O governo é responsável pelo pagamento do benefício, independentemente de contribuição previdenciária.

Enquanto países incentivam pesquisas sobre os benefícios do tratamento medicinal a base da maconha, o Brasil ainda permanece como um dos Estados que não reconhece os poderes terapêuticos. Essa proibição acaba restringindo o direito de inúmeras pessoas que padecem de doenças raras impedindo-as de tratarem-se ou amenizarem os sintomas oriundos desses males com substâncias derivadas e ou até mesmo da própria maconha.

A partir de 2014 foram sendo regulamentadas a legislação para o uso de medicamentos à base da maconha para tratamento, o primeiro foi a RESOLUÇÃO CREMESP $\mathrm{N}^{\circ}$ 268, DE 7 DE OUTUBRO DE 2014; RESOLUÇÃO CFM No 2.113/2014, DE 30 DE OUTUBRO DE 2014; RESOLUÇÃO ANVISA/DC N 17, DE 6 DE MAIO DE 2015; RESOLUÇÃO ANVISA/DC No 66, DE 18 DE MARÇO DE 2016.

No entanto, é relevante frisar que a proibição do uso da maconha para fins terapêuticos feri a Constituição Federal de 1988 em seus artigos 6, 196 e 197 quando a mesma nos garante a preservação da saúde como um direito social. Assim as famílias acabam recorrendo ao tráfico para adquirir tais produtos ou as substâncias vindas de laboratórios caseiros e clandestinos. Outra possibilidade de realizar o tratamento é a concretização judicial deste direito, sobretudo se 
houver sempre em mente o princípio da máxima

efetividade das normas constitucionais.

É fundamental que o Brasil continue investindo em pesquisas para compreender melhor as potenciais implicações dessas restrições ocasionadas pelo zika vírus, por ter sido um dos países mais afetado com esse surto.

\section{REFERÊNCIA}

BRASIL. Constituição 1988. Constituição da República Federativa do Brasil; texto constitucional promulgado em 5 de dezembro de 1988, com as alterações das Emendas Constitucionais $\mathrm{n}^{\circ} 1 / 1992$ a 68/2011, pelo Decreto Legislativo $\mathrm{n}^{\circ} 186 / 2008$ e pelas Emendas Constitucionais de Revisão n 1 a 6/1994. - 35. ed.- Brasília: Câmara dos Deputados, Edições Câmaras, 2012.

BUENO, Flávia Thedim Costa. A resposta regional à emergência do zika: um estudo preliminar. Florianópolis/SC. $3^{\circ}$ Seminário de Relações Internacionais Repensando interesses e desafios para a inserção internacional do Brasil no século XXI 29 e 30 de setembro de 2016.

CARLINI, EA, RODRIGUES E, GALDURÓZ JCF. Cannabis sativa L. e substâncias canabinóides em medicina. São Paulo: CEBRID, 2005.

DIAS, Luiz Cláudio Portinho. O panorama atual da pessoa portadora de deficiência física no mercado de trabalho. Disponível em: <www.ambito-juridico.com.br>. Acessado em: 20 abril de 2017.

DISCACCIATI Ana Clara Gonçalves: A possibilidade de concessão de benefício assistencial a famílias com crianças portadoras de necessidades especiais. Revista da Faculdade de Direito da UFRGS, Porto Alegre, n. 34, p. 238-259, ago. 2016.

FALCÃO, Melissa et al. Guia de manejo da infecção pelo vírus zika. Sociedade Brasileira de Infectologia. 2016.
FRANÇA, Inacia Sátiro Xavier de. et. al. Política de inclusão do portador de deficiência: possibilidades e limites. Acta Paul. Enferm 2008;21(1):112-6.

GONTIÈS, Bernard. Maconha: uma perspectiva histórica, farmacológica e antropológica. Mneme revistas de humanidades. V.4 - N.7 - fev./mar. de 2003.

MARINHO, Fatima e colaboradores.

Microcefalia no Brasil: prevalência e caracterização dos casos a partir do Sistema de Informações sobre Nascidos Vivos (Sinasc), 2000-2015. Epidemiol. Serv. Saúde, Brasília, 25(4):701-712, out-dez 2016.

MENEZES, Leonardo dos Santos. Zika vírus associado à microcefalia. Revista Pato Tocantins V.3, n. 02, 2016.

MORAES, Hérlon. CEIR fará pesquisa inédita para uso do canabidiol em crianças com microcefalia. Disponível em: $<$ http://cidadeverde.com/noticias/246890/ce ir-fara-pesquisa-inedita-para-uso-docanabidiol-em-criancas-com-microcefalia>. Acessado em: 20 abril de 2017.

MOURA, Dionatan Silva de. Maconha medicinal: o direito à saúde versus o uso de substâncias entorpecentes. Jurisway. 2016. Disponível em: < https://www.jurisway.org.br/v2/dhall.asp?id_ $\mathrm{dh}=17470>$. Acessado em: 21 abril de 2017 .

Oliveira CS, da Costa Vasconcelos PF. Microcephaly and Zika virus. J Pediatr (Rio de Janeiro. 2016.

OLIVEIRA, Monique. Justiça autoriza importação de remédio derivado de maconha para criança com epilepsia. Disponível em: <http://www1.folha.uol.com.br/equilibrioesa ude/2014/04/1435521 >. Acessado em: 22 maio de 2017.

OUTTES, Ludmila. Maioria das vítimas de microcefalia são de famílias pobres. $29 \mathrm{de}$ março de 2016. Recife. Disponível em: 
<http://averdade.org.br/2016/03/16188/> . Acessado em: 20 abril de 2017.

VARGAS, Alexandre e colaboradores.

Características dos primeiros casos de
DOI: 10.29247/2358-260X.2018v5i2.p14-28 microcefalia possivelmente relacionados ao vírus Zika notificados na Região Metropolitana de Recife, Pernambuco.

Epidemiol. Serv. Saúde, Brasília, 25(4):691-700, out-dez 2016. 